\title{
Maternal nutrition counselling is associated with reduced stunting prevalence and improved feeding practices in early childhood: a post-program comparison study
}

Sabuj Kanti Mistry ${ }^{1,2}$, Md. Belal Hossain ${ }^{1}$ and Amit Arora ${ }^{3,4,5,6^{*}}$

\begin{abstract}
Background: Despite progress, suboptimal feeding practices and undernutrition particularly in the form of stunting still remains a major issue among children aged less than 5 years in Bangladesh. Since mothers are the primary caregivers of young children, maternal nutrition counselling can be effective in improving knowledge and practices on child feeding. The Building Resources Across Communities (BRAC) initiated a nutrition counselling intervention using its essential health care (EHC) skeleton in 114 sub-districts of Bangladesh in 2012. This study assessed the role of this intervention on the prevalence of stunting and feeding practices among children aged less than 5 years.

Methods: The data was collected as part of a nationwide cross-sectional survey, which followed a two-stage cluster random sampling procedure and was conducted between October 2015 and January 2016. The present study analyzed the information of 3009 mother-children dyads from two selected survey areas: i) areas where the EHC package was delivered (comparison; $n=1452$ ), ii) areas with EHC plus nutrition counselling package (intervention; $n=1557)$ was delivered. The Chi-square test was done to compare the child feeding practices and stunting prevalence between intervention and comparison. The degree of strength of the association of stunting and the intervention was estimated using a mixed-effect logistic regression model.

Results: The study revealed that the prevalence of stunting was significantly lower in areas where the intervention was delivered compared to the comparison areas (29\% vs. 37\%, $P<0.001)$. Furthermore, after adjusting for administrative zone, household wealth quintile, child's age, gender, maternal age, education, occupation, cluster disparity, and variation between study groups, it was seen that the risk of stunting was $25 \%$ lower in the intervention areas compared to the comparison areas (aOR: $0.75,95 \% \mathrm{Cl}: 0.60-0.94 ; P=0.012$ ). Optimal child feeding practices were also more common among mothers from intervention areas than those of the comparison areas (exclusive breastfeeding: 72.7 vs. 59.4\%, $P=0.008$; feeding 4+ food groups: 42.9 vs. $34.1 \%, P<0.001$; having minimum acceptable diet: 31.2 vs. $25.3 \%, P=0.017$; feeding multiple micro-nutrient powder: 16.2 vs. $7.4 \%, P<0.001)$.

(Continued on next page)
\end{abstract}

\footnotetext{
* Correspondence: a.arora@westernsydney.edu.au

${ }^{3}$ School of Science and Health, Western Sydney University Campbelltown

Campus, Locked Bag 1797, Penrith, NSW 2751, Australia

${ }^{4}$ Translational Health Research Institute, Western Sydney University, Locked

Bag 1797, Penrith, NSW 2751, Australia

Full list of author information is available at the end of the article
}

(c) The Author(s). 2019 Open Access This article is distributed under the terms of the Creative Commons Attribution 4.0 International License (http://creativecommons.org/licenses/by/4.0/), which permits unrestricted use, distribution, and reproduction in any medium, provided you give appropriate credit to the original author(s) and the source, provide a link to the Creative Commons license, and indicate if changes were made. The Creative Commons Public Domain Dedication waiver (http://creativecommons.org/publicdomain/zero/1.0/) applies to the data made available in this article, unless otherwise stated. 


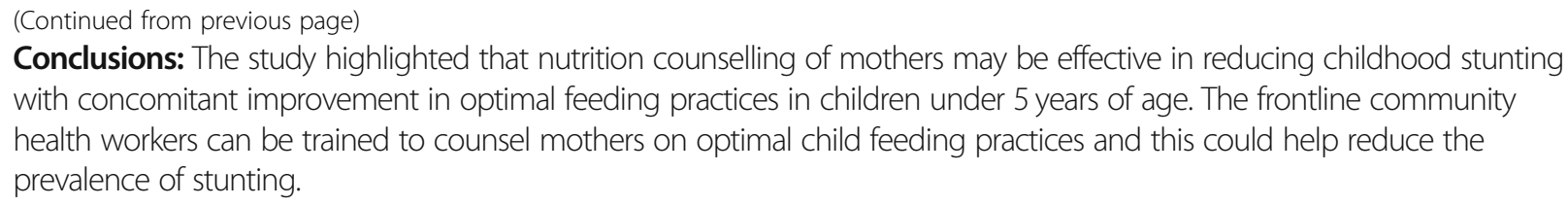

\section{Background}

Globally, 3.1 million children under the age of five years (under-5) die annually due to undernutrition, which is nearly half of all the deaths occurring in children under-5 $[1,2]$. The World Health Organization (WHO) highlights stunting is the most predominant form of undernutrition among children under- 5 and it is estimated that globally around 161 million under-5 are stunted [3].

Although childhood stunting is ubiquitous round the world, it is particularly prevalent in low- and middleincome countries (LMICs) [4, 5]. According to the most recent Demographic and Health Survey, more than one-third (36.1\%) of under-5 children are stunted in Bangladesh [6]. Despite this, Bangladesh is one of the few LMICs which has achieved a considerable reduction in the prevalence of childhood stunting over the last decade $[4,6]$. This progress can heavily be attributed to the collaborative efforts of the Government of Bangladesh, a few development partners, and non-government organizations (NGOs) in implementing several community based healthcare and nutrition interventions [7].

Despite considerable reduction in the prevalence of childhood stunting over the last decade, the reduction rates are relatively slow in Bangladesh [6]. A recent study affirmed that the annual average reduction in the prevalence of stunting is $2.9 \%$ in Bangladesh [8] and with this pace of reduction it is less likely to achieve the World Health Assembly's target of reducing the prevalence of stunting by $40 \%$ before the year 2025 [9-11]. This implies that the government, policy makers, and researchers need to search for effective initiatives to sustain the progress and to accelerate the rate of stunting reduction.

A wealth of evidence generated in resource poor settings highlighted that nutrition education to mothers of young children could significantly increase the knowledge and improve practices on optimal early childhood feeding, which was significantly associated with the lower prevalence of undernutrition among their children [12-14]. In fact, suboptimal feeding practices in childhood has been identified as one the most three prominent drivers of childhood stunting in South Asian countries [15]. Although some studies carried out in resource poor setting reported that maternal nutrition counselling is associated with improved infant and young child feeding (IYCF) practices [16, 17] and reduced childhood stunting [1820], there is limited evidence from Bangladesh.

In 2011, Building Resources Across Communities (BRAC) initiated an intervention in 114 sub-districts of Bangladesh where the community health workers (CHWs) of BRAC namely Sasthya Kormis (SKs) were trained to counsel mothers on childhood nutrition in addition to their primary role of providing basic healthcare services, which was in place since 1991. On the other hand, in 131 sub-districts, the $S K$ s continued to deliver the basic healthcare services [21]. The purpose of this study was to assess the impact of this intervention on the prevalence of stunting and feeding practices among children aged less than 5 years.

\section{Methods}

\section{Study design and participants}

The data used for this study was part of a nationwide cross-sectional health care survey conducted by BRAC between October 2015 and January 2016. The study area was divided into 7 domains with different combinations of major health interventions of BRAC. Totally, it covered 457 sub-districts among 492 sub-districts of Bangladesh as well as the entire urban slums from all of the 11 city corporations of the country.

Essential health care (EHC) is the fundamental health initiative of BRAC which has been in operation since 1991 and currently covering 4.8 million population in 363 subdistricts of rural areas of Bangladesh. All other major health initiatives of BRAC has been established on this EHC backbone except in improving maternal, neonatal and child survival (IMNCS) areas where the EHC model has been restructured into IMNCS model. Thus, at the end of 2011, there were 245 sub-districts with EHC operation only, of which 114 sub-districts were randomly selected where the nutrition package was inserted into the EHC backbone in 2012. Therefore, we considered two domains in present study: i) areas with essential health care (EHC) package only (comparison), ii) areas with EHC package plus nutrition initiative (intervention).

In the 2015-16 survey, a two-stage cluster random sampling procedure was applied and 11,428 households having at least one under- 5 child were selected. In the first stage, 210 enumeration areas (EAs) i.e., 30 EAs from each of the 7 domains were selected randomly, with 180 
EAs from rural areas and thirty EAs from urban slums. An EA is a union (rural areas) or ward (slums), which is the lowest administrative unit in Bangladesh. In the second stage, on an average, fifty-four households were selected per EA through systematic random sampling to provide statistically reliable estimates. If a household had more than one under- 5 child, the youngest child was included in the survey. The details can be found elsewhere [22]. The present analysis was performed among 3009 mother-children dyads; 1452 sampled from comparison areas and 1557 from intervention areas. The detail sampling procedure is presented in Fig. 1.

\section{Overview of EHC and nutrition intervention of BRAC}

EHC delivers low cost basic curative and preventive health care services, particularly focusing on mother and children. Employing frontline CHWs i.e., Shasthya Sebikas (SSs) and Shasthya Karmis (SKs), EHC offers health services through door-to-door visits of the targeted beneficiaries. In fact, this $\mathrm{CHW}$ skeleton is the basis of health intervention of BRAC [21]. SSs are the grass-root CHWs of BRAC, recruited from the target community, married women aged between 25 and 40 years, and at- least primary level of education. They receive 15 days training on basic health care services as well as on health issues of mothers and children under-5, delivered by medical doctors and program personnel. They also join a monthly refresher training to help retain their knowledge and skills. Every SS has a working area of 200-300 households and are supervised by a $S K$, the second layer of CHWs. SKs roughly aged between 20 to 35 years with secondary education completed, and each $S K$ has the responsibility of monitoring 10-12 SSs. SKS receive an intensive 18 days residential training provided by medical doctors and program personnel covering maternal and child health issues as well as on data reporting and delivering antenatal, postnatal, and child care services. Alike $S S$ s, SKs also join monthly refresher training. Both of these CHWs provide treatments for basic ailments and performs tasks such as pregnancy identification, family planning services, antenatal care, assistance in child birth, neonatal and child care, and detection and referral for maternal and childhood complications [23, 24].

In 2012, BRAC initiated a nutrition intervention package in 114 EHC rural sub-districts using the CHWs of BRAC with an aim to improve the nutrition status of the

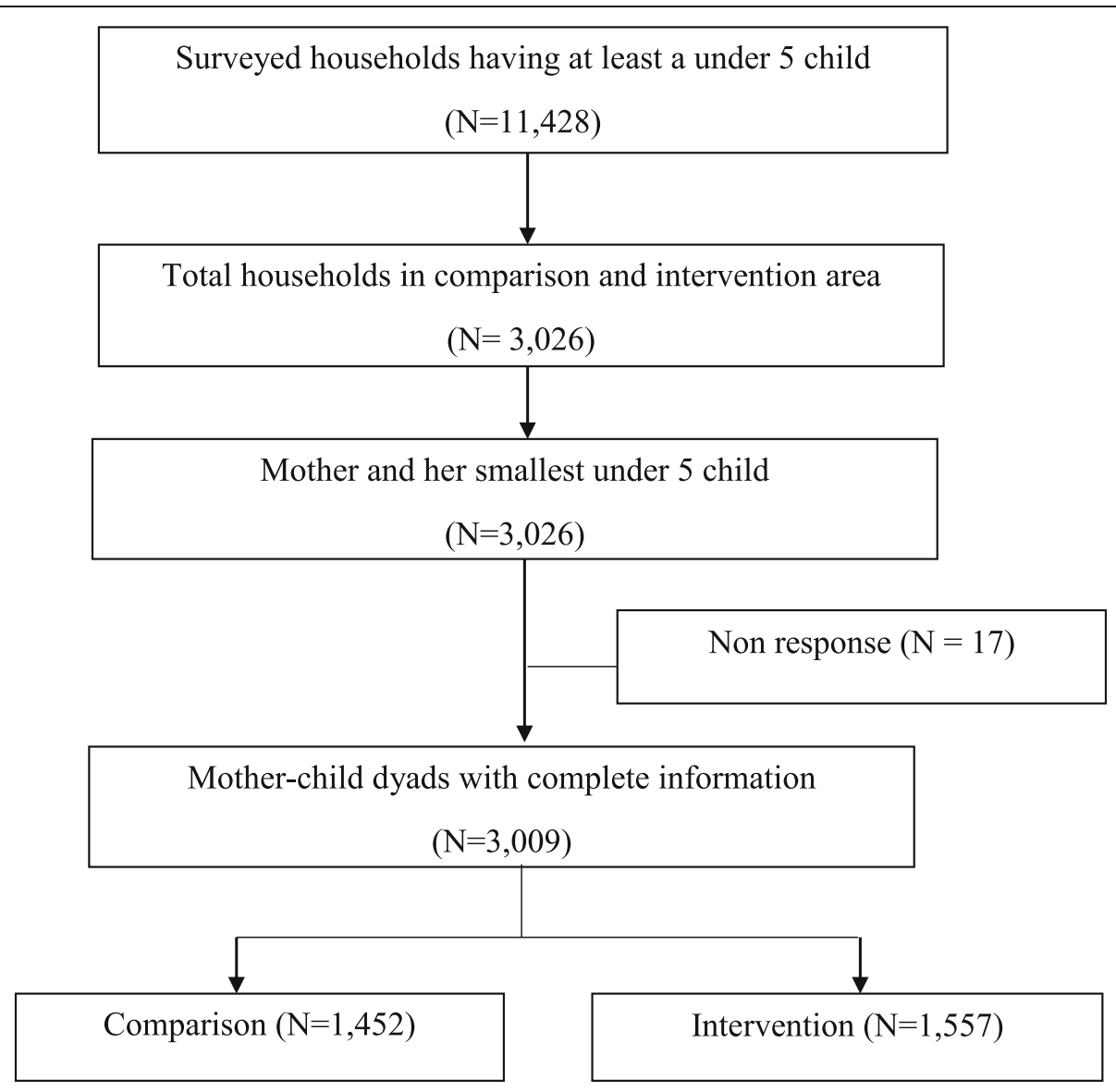

Fig. 1 Study profile and participants enrollment 
under-5 children. The $S K \mathrm{~s}^{\prime}$ in these areas were provided with an intensive training on child nutrition for 7 days. In addition to their regular EHC activities they also performed nutrition counselling targeting mothers of the children under- 5 to promote optimal feeding practices and nutrition in children. SKs were asked to counsel mothers on proper nutrition during pregnancy, ironfolate and calcium supplementation during pregnancy and lactation, importance of breastfeeding, and agespecific complementary feeding in addition to the EHC activities of promotion of antenatal and postnatal health care services.

\section{Data collection tools and techniques}

A pre-tested structured questionnaire was administered to collect the household, mother, and child related information through face-to-face interview of the mothers, while anthropometric measurements of the children were taken using standardized procedures. Collected information was recorded electronically in an android based mobile app, ODK (Open Data Kit), with an efficient user-friendly interface, which is particularly effective in low resource settings. ODK can be performed in both online and offline and can be administered by people with minimal educational attainment [25].

A total of 84 female research assistants with previous experience in conducting heath care survey were hired to conduct the interviews. Since our respondents were women, we preferred female interviewers to minimize reporting bias [26]. They were trained intensively for 15 days with a series of classroom lectures, role play, mock interviews, and field practice. A total of 21 groups were formed, each consisting of four research assistants led by a trained supervisor. Data collection was done in an offline version of ODK and was uploaded in evenings on a daily basis. The server was controlled by an ICT expert at the Dhaka Head Office. A strong monitoring system was set up in place and activities such as spot inspection, questionnaire scrutiny, and back checking was performed to validate and maintain data quality and necessary feedback was provided to the research assistants. The team leader acted as the first level of monitoring while researchers and field managers frequently travelled to the survey areas to supervise data collection. A statistician was also positioned in the Head Office to monitor the flow of data, quality of live data, and to provide immediate feedback to the respective interviewers.

\section{Measures}

Construction of the wealth index was based on factor analysis $[27,28]$ of key socioeconomic variables. The key socioeconomic variables were: types of wall, floor and roof of the house, ownership of radio, television, computer, bicycle, mobile/telephone, refrigerator, wardrobe, table, chair, watch, bed, sewing machine, bike, motor vehicle, livestock, and access to solar, electricity.

Child's age was recorded from the immunization card or in its unavailability, the local event calendar was used. Weight of the children was measured using electronic bathroom scale to the nearest $0.1 \mathrm{~kg}$ precision, while the height was measured by using a locally prepared board with a wooden base in supine position and a movable headpiece, on a flat subject with $0.1 \mathrm{~cm}$ precision. Anthropometric index height-for-age $\mathrm{z}$-score was constructed using WHO Anthro Plus software [29].

Feeding practices were measured through interviewing mothers of the children aged less than two years because the WHO/UNICEF guidelines for IYCF practices should be recorded in children aged $0-23$ months [30]. Prelacteal feeding was defined as children given any food except breast milk within first three days of life, while a child was considered to be exclusively breastfed if he/she did not receive anything except breast milk (even not a drop of water) in the $24 \mathrm{~h}$ preceding the survey [31]. Minimum dietary diversity was defined if children aged 6-23 months received foods from at least 4 out the 7 food groups in the last $24 \mathrm{~h}$ preceding the survey. Minimum meal frequency was defined as breastfed children 6-8 months received 2-3 meals per day, breastfed children 9-23 months received 3 or more meals per day, and non-breastfed children received 4 or more meals per day. The children were considered as having the access to minimum acceptable diet if they satisfied both the conditions of minimum dietary diversity and minimum meal frequency [32]. Meanwhile, children were considered micro-nutrient powder (MNP) fed if they were given one or more multiple MNP sachets and considered effectively MNP fed if given $\geq 60$ sachets in last 6 months prior to the survey [33].

\section{Outcome variable}

The primary outcome of this study was stunting. A child with less than two standard deviations below the median $(-2 \mathrm{SD})$ of the WHO reference population in terms of height-for-age z-score was considered as stunted [34].

\section{Statistical analysis}

Descriptive analysis was performed to assess the distribution of variables. The Chi-square test was used for comparing maternal knowledge, practice, and childhood stunting between comparison and intervention areas with $5 \%$ level of significance. Since the data were nested in nature and there were cluster (union) to cluster variation and disparity between study groups, the mixedeffect logistic regression model by considering cluster variations and study groups as random effects was performed to assess the role of maternal nutrition counselling. The final model was adjusted with administrative 
area, household wealth quintile, child's age, gender, maternal age, education and occupation. The adjusted odds ratio $(\mathrm{aOR})$ and confidence interval $(\mathrm{CI})$ were estimated by considering $5 \%$ level of significance. All analyses were carried out using the statistical software package STATA (Version 13.0).

\section{Results}

\section{Background characteristics}

Among 1452 children from comparison areas, 43.5\% were from the central Bangladesh, $41.2 \%$ from southern Bangladesh, and 13.2\% from the northern part of Bangladesh (Table 1). A total of $41.8 \%$ children were from poor

Table 1 Background characteristics of study population

\begin{tabular}{|c|c|c|c|c|}
\hline \multirow[t]{2}{*}{ Characteristics } & \multicolumn{2}{|l|}{$\mathrm{EHC}$} & \multicolumn{2}{|c|}{ EHC + Nutrition } \\
\hline & $\mathrm{n}$ & $\%$ & $n$ & $\%$ \\
\hline \multicolumn{5}{|l|}{ Administrative zone } \\
\hline North & 223 & 15.36 & 206 & 13.23 \\
\hline Central & 631 & 43.46 & 541 & 34.75 \\
\hline South & 598 & 41.18 & 810 & 52.02 \\
\hline \multicolumn{5}{|l|}{ Household wealth status } \\
\hline Poorest & 301 & 20.73 & 256 & 16.44 \\
\hline Poorer & 307 & 21.14 & 280 & 17.98 \\
\hline Middle & 273 & 18.80 & 346 & 22.22 \\
\hline Richer & 307 & 21.14 & 386 & 24.79 \\
\hline Richest & 264 & 18.18 & 289 & 18.56 \\
\hline \multicolumn{5}{|l|}{ Child age (months) } \\
\hline $0-5$ & 133 & 9.16 & 256 & 16.44 \\
\hline $6-23$ & 636 & 43.80 & 718 & 46.11 \\
\hline $24-59$ & 683 & 47.04 & 583 & 37.44 \\
\hline \multicolumn{5}{|l|}{ Child gender } \\
\hline Male & 729 & 50.21 & 818 & 52.54 \\
\hline Female & 723 & 49.79 & 739 & 47.46 \\
\hline \multicolumn{5}{|l|}{ Maternal age (years) } \\
\hline$<20$ & 126 & 8.68 & 221 & 14.19 \\
\hline $20-29$ & 936 & 64.46 & 955 & 61.34 \\
\hline$\geq 30$ & 390 & 26.86 & 381 & 24.47 \\
\hline \multicolumn{5}{|l|}{ Maternal education } \\
\hline No schooling & 98 & 6.75 & 87 & 5.59 \\
\hline Primary incomplete ${ }^{a}$ & 239 & 16.46 & 258 & 16.57 \\
\hline Primary or secondary incomplete ${ }^{b}$ & 812 & 55.92 & 894 & 57.42 \\
\hline Secondary or higher ${ }^{c}$ & 303 & 20.87 & 318 & 20.42 \\
\hline \multicolumn{5}{|l|}{ Maternal occupation } \\
\hline Housewife & 1380 & 95.04 & 1487 & 95.50 \\
\hline Working outside & 72 & 4.96 & 70 & 4.50 \\
\hline N & 1452 & 100.0 & 1557 & 100.0 \\
\hline
\end{tabular}

${ }^{a}$ Completing grade $1-4,{ }^{b}$ completing grade $5-9$, ${ }^{c}$ completing grade 10 or higher households (20.7\% poorest, $21.1 \%$ poorer). Only $9.2 \%$ children were below 6 months of age while 43.8 and $47.0 \%$ were between 6 and 23 months and 24-59 months of age, respectively. The male-female ratio was close to unity. Approximately two-third mothers aged between 20 and 29 years, and most of the mothers were housewives. Moreover, 6.8\% mothers had no education and $20.9 \%$ had completed grade 10 or more.

Of the 1557 children from intervention areas, 34.8\% resided in central Bangladesh, while 52.0\% were from southern Bangladesh, and $13.2 \%$ from the northern part of Bangladesh (Table 1). A total of $34.4 \%$ children were from poor households (16.4\% poorest, $18.0 \%$ poorer). Approximately $16.4 \%$ children were less than 6 months of age, and nearly 50\% aged between 6 and 23 months. The malefemale ratio was also close to unity. Moreover, $61.3 \%$ mothers were aged between 20 and 29 years, and the percentage of educated mothers and housewives were nearly similar to those in comparison areas (Table 1).

\section{Maternal knowledge on child feeding following intervention}

Although 8.6\% mothers in comparison areas had knowledge on prelacteal feeding, it was significantly lower in the intervention areas (4.1\%) (Table 2). The knowledge on initiation of breastfeeding within the first hour of birth was also significantly higher among mothers from the intervention areas than comparison areas $(89.5 \%$ vs. $84.8 \%, P=0.003)$. Although the percentage of mothers having knowledge on exclusive breastfeeding up to 6 months in both areas were similar, knowledge on initiation of complementary feeding by 7 months was significantly higher in intervention areas $(93.3 \%$ vs. $90.3 \%$, $P=0.019$ ). Moreover, mothers from intervention areas had significantly higher knowledge on dietary diversity for children, i.e., having 4 or more food groups in a day, than comparison areas $(86.8 \%$ vs. $80.0 \%, P<0.001)$ (Table 2$)$.

Maternal practices on child feeding following intervention Although 13.3\% mothers in comparison areas provided prelacteal feed to their child, it was significantly lower in the intervention areas (9.8\%) (Table 3). Moreover, $72.7 \%$ women exclusively breastfed their children (aged less than 6 months) in the last 24-h before the survey in the intervention areas compared to $59.4 \%$ in comparison areas $(P=0.008)$. Although, among mothers with 6-23 months aged children, the practices of initiation of complementary feeding by 7 months was nearly similar in both areas (69.1 and 70.1\% respectively, $P=0.700$ ), child's dietary diversity was significantly higher in intervention areas $(42.9 \%$ vs. $34.1 \%, P=0.001)$. The practices of minimum acceptable diet was also significantly higher in intervention areas ( $31.2 \%$ vs. $25.3 \%, P=0.017)$. The percentage of 6-23 months aged children ever fed or effectively fed MNP in last 6 months were significantly higher in 
Table 2 Maternal knowledge on child feeding in comparison and intervention area

\begin{tabular}{|c|c|c|c|}
\hline Characteristics & $\begin{array}{l}\text { Comparison } \\
\text { area }\end{array}$ & $\begin{array}{l}\text { Intervention } \\
\text { area }\end{array}$ & $p^{1}$ \\
\hline $\begin{array}{l}\text { Number of children aged }<2 \text { years } \\
(\mathrm{N})\end{array}$ & 769 & 974 & \\
\hline Prelacteal feeding (\%) & 8.58 & 4.11 & $\begin{array}{l}< \\
0.001\end{array}$ \\
\hline $\begin{array}{l}\text { Initiation of breastfeeding within } 1 \mathrm{~h} \\
\text { of birth (\%) }\end{array}$ & 84.79 & 89.53 & 0.003 \\
\hline $\begin{array}{l}\text { Exclusive breastfeeding up to } 6 \\
\text { months (\%) }\end{array}$ & 89.99 & 91.99 & 0.144 \\
\hline $\begin{array}{l}\text { Initiation of complementary feeding } \\
\text { by } 7 \text { month (\%) }\end{array}$ & 90.25 & 93.33 & 0.019 \\
\hline Having $4+$ food groups in a day (\%) & 79.97 & 86.76 & $\begin{array}{l}< \\
0.001\end{array}$ \\
\hline
\end{tabular}

${ }^{1} P$-value for the Chi-square test between comparison and intervention areas

intervention areas $(16.2 \%$ vs. $7.4 \%, P<0.001$ and $3.76 \%$ vs. $0.9 \%, P=0.001$ respectively) (Table 3 ).

\section{Nutritional status of under- 5 children}

The prevalence of stunting among under- 5 children was significantly lower in intervention areas than comparison areas $(28.8 \%$ vs. $37.2 \%, P<0.001)$ (Table 4$)$. After adjusting for potential confounders in the mixed effect logistic regression model, it was found that the children from intervention area had 25\% lower odds of being stunted than those from comparison area (aOR: 0.75, 95\% CI: $0.60-0.94, P=0.012$ ).

\section{Discussion}

The present study is an attempt towards assessing the role of a nutrition intervention in the form of nutrition counselling of mothers in reduction of stunting prevalence among under-5 children in Bangladesh.
Nutrition counselling has often been considered as an effective tool for increasing maternal knowledge and practices on optimal child feeding. However, there is lack of evidence on rigorous assessment of the effectiveness of these initiatives in Bangladesh. The present study is one of the few studies carried out in Bangladesh assessing the effectiveness of nutrition counselling in attaining improved nutritional status among young children.

Overall, the study reported that the prevalence of stunting was significantly lower among children from intervention areas where mothers of these children received the nutrition counselling. We also found that nutrition counselling had a positive role on increasing some of the optimal IYCF practices, which might have resulted in significant reduction in stunting prevalence among children. Other researchers have pointed that attainment of optimal nutrition in early childhood is largely dependent on ensuring optimal IYCF practices [7, 35-37].

Optimal IYCF practices have been defined by the World Health Organization (WHO) as early initiation of breastfeeding within the first hour of delivery, exclusive breastfeeding for up to six months of life, introducing nutritionally rich complementary foods after six months of age and continued breastfeeding till two years of life [32]. We found that maternal practices on early initiation of breastfeeding (within one hour of birth), which is particularly crucial for neonatal survival [38], was significantly higher in intervention areas. Early initiation of breastfeeding also promotes prolonged period of exclusive breastfeeding [39], and it is recommended that children should be exclusively breastfed for 6 months of life to achieve proper growth and development [40]. The present study also reported that exclusive breastfeeding was significantly higher in the intervention areas. Furthermore, higher

Table 3 Maternal practices on child feeding in comparison and intervention area

\begin{tabular}{lll}
\hline Characteristics & Comparison area & Intervention area \\
\hline Number of children aged $<2$ years (N) & 769 & 974 \\
Prelacteal feeding (\%) & 13.26 & 9.75 \\
Initiation of breastfeeding within 1 h of birth (\%) & 65.93 & 68.99 \\
Number of children aged $<6$ months (N) & 133 & 256 \\
Exclusive breastfeeding (\%) & 59.40 & 72.66 \\
Number of children aged 6-23 months (N) & 612 & 699 \\
Initiation of complementary feeding by 7 month (\%) & 69.12 & 70.10 \\
Having 4+ food groups out of 7 groups in last 24 $\mathrm{h}(\%)$ & 34.12 & 42.90 \\
Minimum acceptable diet in last 24 $\mathrm{h}(\%)$ & 25.31 & 31.20 \\
Ever fed multiple micro-nutrient powder in last 6 months (\%) & 7.39 & 16.16 \\
Effectively fed multiple micro-nutrient powder in last 6 months (\%) & 0.94 & 3.76 \\
\hline
\end{tabular}

${ }^{1} 7$ food groups: 1) grains, roots and tubers; 2) legumes and nuts; 3 ) dairy products (milk, yogurt, cheese); 4) flesh foods (meat, fish, poultry and liver/organ meats); 5) eggs; 6) vitamin-A rich fruits and vegetables; 7) other fruits and vegetables

${ }^{2} P$-value for the Chi-square test between comparison and intervention areas 
Table 4 Stunting among under-5 children in comparison and intervention area

\begin{tabular}{|c|c|c|c|c|c|}
\hline \multirow[t]{2}{*}{ Characteristics } & \multirow{2}{*}{$\begin{array}{l}\text { Stunting } \\
\%(95 \% \mathrm{Cl})\end{array}$} & \multicolumn{2}{|l|}{ Unadjusted } & \multicolumn{2}{|l|}{ Adjusted $^{\mathrm{a}}$} \\
\hline & & OR $(95 \% \mathrm{Cl})$ & $P$ & OR (95\% Cl) & $P$ \\
\hline \multicolumn{6}{|l|}{ Area } \\
\hline Comparison & 37.19 (34.74-39.71) & 1.00 & & 1.00 & \\
\hline Intervention & $28.77(26.58-31.07)$ & $0.69(0.55-0.87)$ & 0.002 & $0.75(0.60-0.94)$ & 0.012 \\
\hline
\end{tabular}

${ }^{a}$ OR adjusted with administrative zone, household wealth quintile, child's age, gender, maternal age, education, occupation, cluster disparity and variation between study groups

number of children from the intervention areas fulfilled minimum dietary diversity requirement of eating food items from at least 4 food groups, which is particularly important for the children to attain proper nutrition [41, 42]. A few studies $[16,17]$ carried out in similar settings also reported that counselling mothers on child feeding practices is associated with overall improvement in optimum infant and child feeding practices. Although, some studies found that maternal nutrition counselling results in reduced childhood stunting $[19,20]$, other studies $[43,44]$ reported that nutrition counselling were ineffective in reduction of stunting among young children. However, it was also reported through conducting a meta-analysis that nutrition education is effective in reducing stunting among young children when it is complemented with interventions such as food or micronutrient supplementation or nutrition safety net programs [45]. The positive correlation between maternal nutrition counselling and reduced stunting prevalence among young children in this study may be attributable to involving female community health workers and effective program monitoring.

The present study found that maternal knowledge on optimal child feeding practices was significantly higher in intervention areas compared to the comparison areas. The improvement in optimal child feeding practices in intervention areas might have been achieved due to this high level of maternal knowledge on child feeding practices. Studies carried out in similar settings also reported that maternal knowledge on child feeding is positively correlated with the child feeding practices and improved nutritional status among young children [46, 47]. The present research also pointed that face-to-face nutrition counselling to the mother is effective in increasing maternal knowledge as well as achieving proper IYCF practices among children. A previous study carried out in Dhaka, Bangladesh also reported that maternal nutrition education helps in motivating mothers to exclusively breastfed their children for up to 6 months [48]. Several other studies conducted in resource poor settings also pointed that maternal counselling on child feeding is effective for improving child feeding practices through increasing maternal knowledge on child feeding $[14,16,49]$.

Bangladesh has a well-structured healthcare system with health facilities readily available. It has a setup of community clinics, one for each 6000 people, and CHWs are employed in the clinics with the role of community health service. They provide basic preventive and curative health services to the community, similar to that of the CHWs of BRAC EHC. However, with the goal of achieving strict targets on health outcomes, nutrition issues lose its importance on many occasions [7]. Therefore, to sustain the progress childhood stunting reduction and to accelerate the reduction rates, the government may initiate nutrition education to mothers through providing nutrition training to $\mathrm{CHWs}$. At the same time, the government also needs to establish a strong monitoring system to ensure quality health and nutrition services at the community level.

The study result should be interpreted with caution as it was subjected to certain limitations. Firstly, no baseline information on childhood stunting was available, we were unable to rule out the possibility that the intervention children were less stunted at the outset. It is likely that not having these measurements before the intervention may result in a weak study design and therefore, a randomized controlled trial is recommended where the intervention group mothers receive the nutrition counselling by trained CHWs alongside the usual care while the comparison arm mothers receive the usual care. Second, one should interpret the results with caution considering differences in statistical and clinical significance. We caution the readers that they should pay attention to the actual differences between the groups as in some cases the differences were small to be meaningful even though the differences are statistically significant. Third, childhood stunting might be influenced by the parental biological factors which were not considered in the present study. Fourth, as the study follows a crosssectional design, it may subjected to reporting bias. Finally, a number of factors such as repeated infections, worm infestation, and maternal hygiene and sanitation practices pertaining to the children was not recorded.

\section{Conclusions}

The present study suggested that counselling mothers on child feeding practices may be effective in reducing the prevalence of stunting among under-five children. The finding is particularly crucial from policy perspectives, suggesting that provision of training on nutrition counselling to frontline community health workers can effectively motivate mothers to ensure proper feeding practices to their children. 


\section{Acknowledgements}

We acknowledge the role of the relevant program personnel of BRAC for initial review of the tools and smooth arrangement of the data collection initiatives.

\section{Authors' contributions}

SKM and MBH conceived and designed the study. MBH and SKM conducted the data analysis and participated in the result interpretation. SKM and MBH wrote the first draft of the manuscript. AA revised the manuscript extensively and provided important intellectual inputs. All authors read and approved the final manuscript. The funders had no role in the design, analysis or writing of this manuscript.

\section{Funding}

This research was funded by the Strategic Partnership Arrangement (SPA) between BRAC, the UK Department for International Development (DFID), and the Australian Department of Foreign Affairs and Trade (DFAT).

\section{Availability of data and materials}

The datasets used and/or analyzed during the current study are available from the corresponding author on reasonable request.

\section{Ethics approval and consent to participate}

Ethical approval was obtained from the Bangladesh Medical Research Council (Ref: BMRC/NREC/2013-2016/802) before the study. The objectives of the research were described and informed consent was sought from the parents of the children prior to the interview. They were also ensured that the information they provided will be kept confidential.

\section{Consent for publication}

Not applicable.

\section{Competing interests}

The authors declare that they have no competing interests.

\section{Author details}

${ }^{1}$ BRAC James P Grant School of Public Health, BRAC University, 68 Shahid Tajuddin Ahmed Sharani, Mohakhali, Dhaka 1212, Bangladesh. ${ }^{2}$ Centre for Primary Health Care and Equity, University of New South Wales, Sydney, Australia. ${ }^{3}$ School of Science and Health, Western Sydney University Campbelltown Campus, Locked Bag 1797, Penrith, NSW 2751, Australia. ${ }^{4}$ Translational Health Research Institute, Western Sydney University, Locked Bag 1797, Penrith, NSW 2751, Australia. ${ }^{5}$ Discipline of Child and Adolescent Health, Sydney Medical School, Faculty of Medicine and Health, The University of Sydney, Westmead, NSW 2145, Australia. ${ }^{6}$ Oral Health Services, Sydney Local Health District and Sydney Dental Hospital, NSW Health, Surry Hills, NSW 2010, Australia.

\section{Received: 17 January 2019 Accepted: 15 August 2019}

\section{Published online: 27 August 2019}

\section{References}

1. UNICEF. Malnutrition: current status + Progress [internet]. 2018 [cited 2018 Mar 7]. Available from: https://data.unicef.org/topic/nutrition/malnutrition/.

2. Bhutta ZA, Das JK, Rizvi A, Gaffey MF, Walker N, Horton S, et al. Evidencebased interventions for improvement of maternal and child nutrition: what can be done and at what cost? Lancet. 2013;382:452-77 Elsevier.

3. de Onis M, Branca F. Childhood stunting: a global perspective. Matern Child Nutr. 2016;12:12-26.

4. Black RE, Victora CG, Walker SP, Bhutta ZA, Christian P, De Onis M, et al. Maternal and child undernutrition and overweight in low-income and middle-income countries. Lancet. 2013:382:427-51.

5. Black RE, Allen LH, Bhutta ZA, Caulfield LE, de Onis M, Ezzati M, et al. Maternal and child undernutrition: global and regional exposures and health consequences. Lancet. 2008;371:243-60.

6. National Institute of Population Research and Training, ICF International, Mitra and Associates. Bangladesh Demographic and Health Survey 2014 [Internet]. Dhaka, Rockville. 2014. Available from: http://dhsprogram.com/ pubs/pdf/FR311/FR311.pdf.
7. Ahmed T, Mahfuz M, Ireen S, Ahmed AMS, Rahman S, Islam MM, et al Nutrition of children and women in Bangladesh: trends and directions for the future. J Health Popul Nutr BioMed Central. 2012;30:1.

8. Hossain MB, Khan MHR. Role of parental education in reduction of prevalence of childhood undernutrition in Bangladesh. Public Health Nutr. 2018;2:1-10 Available from: https:/www.cambridge.org/core/product/ identifier/S1368980018000162/type/journal_article.

9. WHO. Global nutrition targets 2025 policy brief series [internet]. WHO Int 2014. Available from: http://apps.who.int/iris/bitstream/10665/149018/1/ WHO_NMH_NHD_14.2_eng.pdf.

10. Haddad L, Achadi E, Bendech MA, Ahuja A, Bhatia K, Bhutta Z, et al. The global nutrition report 2014: actions and accountability to accelerate the World's Progress on nutrition. J Nutr. 2015;145:663-71. Available from: http://jn.nutrition.org/cgi/doi/10.3945/jn.114.206078.

11. Ahmed T, Hossain M, Mahfuz M, Choudhury N, Ahmed S. Imperatives for reducing child stunting in Bangladesh. Matern Child Nutr. 2016;12:242-5.

12. Morrow AL, Guerrero ML, Shults J, Calva JJ, Lutter C, Bravo J, et al. Efficacy of home-based peer counselling to promote exclusive breastfeeding: a randomised controlled trial. Lancet. 1999;353:1226-31.

13. Bhandari N, Kabir IAKM, Salam MA. Mainstreaming nutrition into maternal and child health programmes: scaling up of exclusive breastfeeding. Matern Child Nutr. 2008;4:5-23.

14. Sethi V, Kashyap S, Seth V. Effect of nutrition education of mothers on infant feeding practices. Indian J Pediatr. 2003;70:463-6 Available from: http://www.positivedeviance.org/pdf/publications_maternalchildhealth/ SETHIfeedingpractices.pdf.

15. Smith LC, Haddad L. Reducing child undernutrition: past drivers and priorities for the post-MDG era. World Dev. 2015;68:180-204.

16. Ickes SB, Baguma C, Brahe CA, Myhre JA, Adair LS, Bentley ME, et al. Maternal participation in a nutrition education program in Uganda is associated with improved infant and young child feeding practices and feeding knowledge: a post-program comparison study. BMC Nutr BioMed Central. 2017;3:32.

17. Reinsma K, Nkuoh G, Nshom E. The potential effectiveness of the nutrition improvement program on infant and young child feeding and nutritional status in the northwest and southwest regions of Cameroon, Central Africa. BMC Health Serv Res. 2016;16:1-9.

18. Hossain $M$, Choudhury $N$, Abdullah KAB, Mondal $P$, Jackson AA, Walson J, et al. Evidence-based approaches to childhood stunting in low and middle income countries: a systematic review. Arch Dis Child. 2017;102: 903-9.

19. Kalimbira AA, MacDonald C, Simpson JR. The impact of an integrated community-based micronutrient and health programme on stunting in Malawian preschool children. Public Health Nutr. 2010;13:720-9.

20. Remans R, Pronyk PM, Fanzo JC, Chen J, Palm CA, Nemser B, et al. Multisector intervention to accelerate reductions in child stunting: an observational study from 9 sub-Saharan African countries. Am J Clin Nutr. 2011;94:1632-42.

21. BRAC. Health, nutrition and population Programme [internet]. 2018 [cited 2018 Mar 6]. Available from: http://www.brac.net/health,

22. Mistry SK, Jhohura FT, Khanam F, Akter F, Khan S, Yunus FM, et al. An outline of anemia among adolescent girls in Bangladesh: findings from a cross-sectional study. BMC Hematol BMC Hematol. 2017;17:1-8.

23. Rahman M, Yunus FM, Shah R, Jhohura FT, Mistry SK, Quayyum T, et al. A controlled before-and-after perspective on the improving maternal, neonatal, and child survival program in rural Bangladesh: an impact analysis. PLoS One. 2016:11:1-16.

24. Rahman M, Jhohura FT, Mistry SK, Chowdhury TR, Ishaque T, Shah R, et al. Assessing community based improved maternal neonatal child survival (IMNCS) program in rural Bangladesh. PLoS One. 2015;10:1-15.

25. DeRenzi B, Borriello G, Jackson J, Kumar VS, Parikh TS, Virk P, et al. Mobile phone tools for field-based health care workers in low-income countries. Mt Sinai J Med A J Transl Pers Med. 2011;78:406-18 Wiley Online Library.

26. Davis RE, Couper MP, Janz NK, Caldwell CH, Resnicow K. Interviewer effects in public health surveys. Health Educ Res. 2010;25:14-26.

27. Johnson RA, Wichern D. Multivariate analysis. 6th ed: Wiley Online Library; 2014

28. Rutstein SO. Steps to constructing the new DHS wealth index [Internet] Rockville, MD ICF Int. Maryland; 2015. Available from: https://dhsprogram. com/programming/wealth/index/Steps_to_constructing_the_new_DHS Wealth_Index.pdf. 
29. WHO. AnthroPlus for personal computers. Manual: software for assessing growth of the world's children and adolescents. Geneva: World Health Organization; 2007.

30. WHO, UNICEF. Indicators for assessing infant and young child feeding practices. Geneva: World Health Organization; 2010.

31. WHO. Exclusive breastfeeding for six months best for babies evenywhere [Internet]. World Heal. Organ. 2011 [cited 2018 Mar 6]. Available from: http// www.who.int/mediacentre/news/statements/2011/breastfeeding_20110115/en/

32. WHO \& UNICEF. Global strategy for infant and young child feeding. Geneva: World Health Organization; 2003.

33. Mistry SK, Akter F, Mukta US, Chakraborty B, Rahman M. Exploration of multiple micronutrient powder (MNP) usage among children of 6-59 months in Bangladesh MIYCN - home fortification Programme (MIYCN, phase II) areas [Internet]. Dhaka; 2016. Available from: http://research.brac. net/new/publications/download/355 b9093ba5891d6aaf3cb4e505174c50f8

34. WHO. WHO child growth standards: length/height for age, weight-for-age, weight-for-length, weight-for-height and body mass index-for-age, methods and development. Geneva: World Health Organization; 2006. Available from: http://www.who.int/childgrowth/standards/Technical_report.pdf

35. Sinhababu A, Mukhopadhyay DK, Panja TK, Saren AB, Mandal NK, Biswas AB. Infant-and young child-feeding practices in Bankura district, West Bengal, India. J Health Popul Nutr. 2010;28:294 BioMed Central.

36. Lamichhane DK, Leem JH, Kim HC, Park MS, Lee JY, Moon SH, et al. Association of infant and young child feeding practices with undernutrition: evidence from the Nepal demographic and health survey. Paediatr Int Child Health. 2016;36:260-9 Taylor \& Francis.

37. Bhutta ZA, Ahmed T, Black RE, Cousens S, Dewey K, Giugliani E, et al. What works? Interventions for maternal and child undernutrition and survival. Lancet. 2008;371:417-40 Elsevier.

38. Edmond K, Newton S, Hurt L, Shannon CS, Kirkwood BR, Mazumder S, et al. Timing of initiation, patterns of breastfeeding, and infant survival: prospective analysis of pooled data from three randomised trials. Lancet Glob Heal World Health Organization. 2016;4:e266-75.

39. WHO. Early initiation of breastfeeding to promote exclusive breastfeeding [Internet]. World Heal. Organ. 2017 [cited 2018 Mar 6]. Available from: http:// www.who.int/elena/titles/early_breastfeeding/en/

40. UNICEF. Programming guide infant and young child feeding. Nutr Sect UNICEF. 2011;173.

41. Arimond M, Ruel MT. Dietary diversity is associated with child nutritional status: evidence from 11 demographic and health surveys. J Nutr. 2004;134: 2579-85 Oxford University Press.

42. Ogechi UP, Chilezie OV. Assessment of dietary diversity score, nutritional status and socio-demographic characteristics of Under-5 children in some rural areas of Imo state. Nigeria. 2017;23:425-35.

43. Nikièma L, Huybregts L, Martin-Prevel Y, Donnen P, Lanou H, Grosemans J, et al. Effectiveness of facility-based personalized maternal nutrition counseling in improving child growth and morbidity up to 18 months: a cluster-randomized controlled trial in rural Burkina Faso. PLoS One. 2017;12(5):e0177839.

44. Dewey KG. Reducing stunting by improving maternal, infant and young child nutrition in regions such as South Asia: evidence, challenges and opportunities. Matern Child Nutr. 2016;12:27-38.

45. Girard AW, Olude O. Nutrition education and counselling provided during pregnancy: effects on maternal, neonatal and child health outcomes. Paediatr Perinat Epidemiol. 2012;26:191-204.

46. Jemide JO, Ene-Obong HN, Edet EE, Udoh EE. Association of maternal nutrition knowledge and child feeding practices with nutritional status of children in Calabar south local government area, Cross River state. Nigeria. Int J Home Sci. 2016;2:293-8.

47. Berisha M, Ramadani N, Hoxha R, Gashi S, Zhjeqi V, Zajmi D, et al. Knowledge, attitudes and practices of mothers in kosova about complementary feeding for infant and children 6-24 months. Med Arch. 2017;71:37 The Academy of Medical Sciences of Bosnia and Herzegovina.

48. Roy SK, De Groot S, Shafique S, Afroz A. Perceptions of mothers and use of breastmilk substitutes in Dhaka, Bangladesh. J Heal Popul Nutr. 2002:264-70 JSTOR.

49. Faruque ASG, Ahmed AMS, Ahmed T, Islam MM, Hossain MI, Roy SK, et al. Nutrition: basis for healthy children and mothers in Bangladesh. J Health Popul Nutr. 2008;26:325 BioMed Central.

\section{Publisher's Note}

Springer Nature remains neutral with regard to jurisdictional claims in published maps and institutional affiliations.

\section{Ready to submit your research? Choose BMC and benefit from}

- fast, convenient online submission

- thorough peer review by experienced researchers in your field

- rapid publication on acceptance

- support for research data, including large and complex data types

- gold Open Access which fosters wider collaboration and increased citations

- maximum visibility for your research: over $100 \mathrm{M}$ website views per year

At BMC, research is always in progress.

Learn more biomedcentral.com/submissions 